\title{
Optimal management of renal artery fibromuscular dysplasia
}

This article was published in the following Dove Press journal:

Therapeutics and Clinical Risk Management

28 July 2014

Number of times this article has been viewed

\section{Anders Gottsäter \\ Bengt Lindblad}

Department of Vascular Diseases, Skåne University Hospital, Malmö, Sweden
Correspondence: Anders Gottsäter Department of Vascular Diseases, Skåne University Hospital, S-205 02 Malmö, Sweden

Tel +467 $6887 \quad 1074$

Email anders.gottsater@med.lu.se
Abstract: Fibromuscular dysplasia (FMD) is a nonatherosclerotic, noninflammatory angiopathy of unknown cause affecting medium-sized (most commonly renal) arteries and causing renovascular hypertension. The most common medial multifocal type of FMD (with the "string of beads" appearance) is more than four times more prevalent in females than in males. FMD accounts for up to $10 \%$ of cases of renovascular hypertension. Compared with patients with atherosclerotic renal artery stenosis, patients with FMD are younger, have fewer risk factors for atherosclerosis, and a lower occurrence of atherosclerosis in other vessels. The etiology is multifactorial, including vessel wall ischemia and smoking, as well as hormonal and genetic factors. Intra-arterial digital subtraction angiography is still the gold standard for exclusion or confirmation of renal artery stenosis caused by FMD, at least in young patients, who more often have lesions in branches of the renal artery. For FMD patients with atherosclerosis and those who are older ( $>50-55$ years), significant renal artery stenosis may be confirmed or excluded with ultrasonography. The FMD lesion is typically truncal or distal, whereas atherosclerotic lesions are more often proximal or ostial. Treatment options are medical, endovascular (percutaneous transluminal renal angioplasty [PTRA]), and surgical. Invasive treatment should be considered when hypertension cannot be controlled with antihypertensive drugs and in patients with impaired renal function or ischemic nephropathy. PTRA has become the treatment of choice and normally yields good results, especially in unifocal disease and young patients. Pressure gradients are normally completely abolished, and there is no indication for stent placement. Surgical revascularization is indicated after PTRA complications; thrombosis, perforation, progressive dissection, repeated PTRA failure or restenosis. Centralization of handling is recommended.

Keywords: fibromuscular dysplasia, renal artery stenosis, arterial hypertension, percutaneous transluminal renal angioplasty, renal artery surgery

\section{Background}

One criticism of the ASTRAL (Angioplasty and Stenting for Renal Artery Lesions) ${ }^{1}$ and STAR (STent placement and blood pressure and lipid-lowering for the prevention of progression of renal dysfunction caused by Atherosclerotic ostial stenosis of the Renal artery $)^{2}$ trials in atherosclerotic renal artery stenosis is that patients with moderate hypertension and a moderate degree of stenosis were included, making the results uncertain. In the recent CORAL (Cardiovascular Outcomes in Renal Atherosclerotic Lesions) trial, ${ }^{3}$ the effects of percutaneous renal artery stenting combined with medical therapy were compared with those of medical therapy alone in 950 patients with pronounced hypertension and at least $60 \%$ stenosis. This trial replicated earlier findings of no benefit of renal artery stenting with regard to cardiovascular events or renal 
function, ${ }^{3}$ establishing beyond reasonable doubt that patients with $<70 \%-80 \%$ atherosclerotic renal artery stenosis, stable renal function, and up to two antihypertensive drugs should not undergo renal artery stenting since there is no gain.

These new data might also have relevance in terms of treatment recommendations for patients who have renovascular hypertension with an etiology other than atherosclerosis. This review of fibromuscular dysplasia (FMD), a nonatherosclerotic, noninflammatory angiopathy of unknown cause affecting medium-sized (most commonly renal) arteries and causing renovascular hypertension, is based on information that is as current as possible.

\section{Epidemiology}

Symptomatic renal artery stenosis caused by FMD occurs in $0.4 \%$ of the population, ${ }^{4}$ but the prevalence of asymptomatic FMD in potential renal donors is $2.6 \%-4 \% \%^{4-6}$ and bilateral in about one third of cases. FMD is most often diagnosed in individuals aged $15-70$ years, ${ }^{7,8}$ but has been reported to occur from infancy ${ }^{9}$ to the age of 89 years. ${ }^{10}$ The medial multifocal type (Figure 1) of FMD is most common $(68 \%-91 \%)^{8,11}$ and is more than four times more prevalent in females than in males, ${ }^{4,8,11}$ whereas the less common unifocal intimal type (Figure 2) is more prevalent in men. ${ }^{4,12}$ The male to female ratio is $1: 4.5$ according to the studies summarized in Tables 1 and 2. Bilateral lesions occur in about $25 \%-65 \%$ of cases, requiring bilateral treatment in $15 \%-25 \%{ }^{8,11}$ In unilateral disease, the right renal artery was found to be affected three times more often than the left. ${ }^{8}$ FMD accounts for up to $10 \%$ of cases of renovascular hypertension, ${ }^{13}$ with the remainder being caused mainly by atherosclerosis. Compared with patients who have atherosclerotic renal artery stenosis, FMD patients tend to be female, younger, and have fewer risk factors for atherosclerosis and a lower occurrence of atherosclerosis in other vessels. ${ }^{4,811}$ FMD is diagnosed more often in whites and less frequently in Hispanic and Asian populations. Few reports

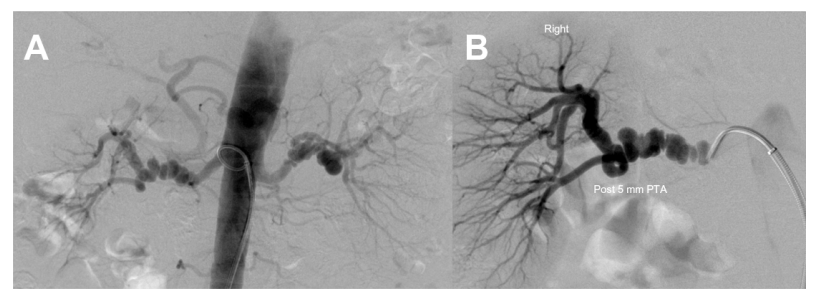

Figure I Typical selective angiographic multifocal appearance of medial fibrodysplasia with "string of beads" appearance in the distal main artery before (A) and after (B) PTA. Note: It is difficult to visualize that the $45 \mathrm{mmHg}$ pressure gradient disappeared and a favorable effect on blood pressure was achieved.

Abbreviation: PTA, percutaneous transluminal angioplasty.

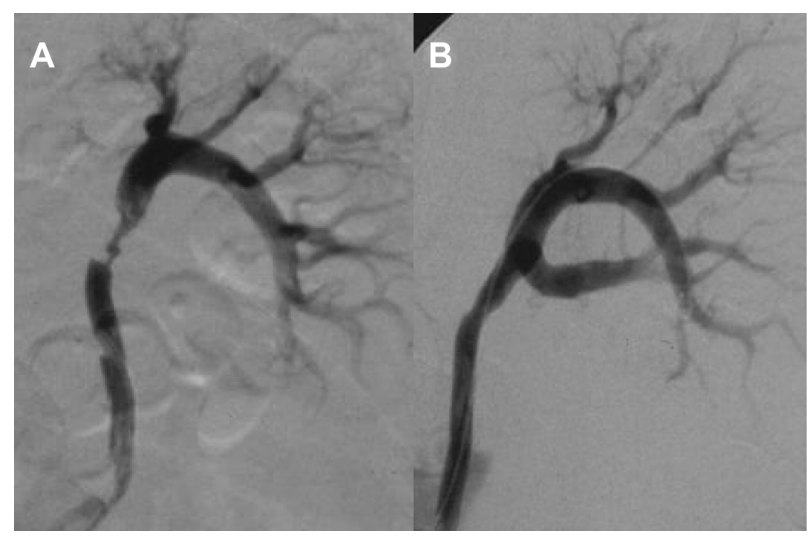

Figure $\mathbf{2}$ Short unifocal stenosis of the distal main artery, perhaps of the perimedial dysplastic type, before (A) and after (B) percutaneous transluminal angioplasty.

have been published from Africa and South America. ${ }^{11}$ In the US FMD Registry, which contains data for 447 patients, 95\% were white, only $2 \%$ were African Americans, and $1 \%$ were Hispanic or Asian. ${ }^{8}$ Other vessels, such as the carotid, vertebral, mesenteric, and coronary arteries, were frequently affected. Two vascular beds were found to be affected in $35 \%$ of patients and three in $22 \%$, underscoring the need for a good clinical examination and at least carotid artery investigation in FMD patients. ${ }^{8}$

The causes of pediatric renal artery stenosis differ in different populations. ${ }^{9}{ }^{14-16}$ FMD is the most common cause of pediatric renovascular hypertension in North America and Western Europe, whereas Takayasu's arteritis dominates in Asia and Africa.

\section{Etiology}

Vessel wall ischemia seems to be of relevance for the development of FMD. ${ }^{17}$ The vasa vasorum of the muscular arteries supplying oxygen and nutrients to the arterial wall originate from branch points of the parent arteries. Experimental occlusion of the vasa vasorum induces formation of dysplastic lesions. ${ }^{18}$ The vessels most frequently affected by FMD, ie, the renal, internal carotid, and vertebral arteries, have long segments that lack branches.

The female preponderance of FMD suggests the importance of hormonal factors such as estrogen and progesterone. ${ }^{8,19,20}$ In one study, $16 \%$ of women with FMD had previous hypertension in pregnancy compared with $4 \%-5 \%$ of hypertensive pregnancies in the general population. ${ }^{21}$ FMD has also been diagnosed after ovarian stimulation. ${ }^{22}$ However, the number of pregnancies and frequency of use of oral contraception or hormone therapy is not higher in FMD patients than in the general population. ${ }^{8,22,23}$ Young men with FMD often have 
Table I Results of percutaneous transluminal renal angioplasty for fibromuscular dysplasia in adults

\begin{tabular}{|c|c|c|c|c|c|c|c|}
\hline Series & Year & $\begin{array}{l}\text { Patients } \\
\text { (n) }\end{array}$ & $\begin{array}{l}\text { Female } \\
\text { (n) }\end{array}$ & $\begin{array}{l}\text { Cure } \\
(\%)\end{array}$ & $\begin{array}{l}\text { Improvement } \\
(\%)\end{array}$ & $\begin{array}{l}\text { Failure } \\
\text { (\%) }\end{array}$ & $\begin{array}{l}\text { Length of follow- } \\
\text { up (months) }\end{array}$ \\
\hline Sos et al & 1983 & 31 & 27 & 59 & 34 & 7 & 16 \\
\hline Martin et al & 1985 & 21 & 21 & 25 & 60 & 15 & 16 \\
\hline Lüscher et al & 1986 & 31 & 24 & 50 & 39 & 11 & 15 \\
\hline Hägg et al & 1987 & 19 & 16 & 33 & 22 & 44 & 23 \\
\hline Greminger et al & 1989 & 34 & 23 & 41 & 47 & 12 & 24 \\
\hline Klinge et al & 1989 & 52 & 43 & 40 & 48 & 12 & 60 \\
\hline Baert et al & 1990 & 22 & 18 & 58 & 24 & 12 & 25 \\
\hline Tegtmeyer et al & 1991 & 66 & 59 & 41 & 57 & 2 & 39 \\
\hline Simonetti et al & 1993 & 442 & NA & 64 & 25 & 11 & 93 \\
\hline Rodriguez et al & 1994 & 27 & 17 & 43 & 48 & 10 & 96 \\
\hline Cluzel et al & 1994 & 20 & 15 & 65 & 30 & 5 & 19 \\
\hline Bonelli et al & 1995 & 105 & 91 & 22 & 41 & 37 & 43 \\
\hline Jensen et al & 1995 & 30 & 20 & 39 & 47 & 14 & 12 \\
\hline Karagiannis et al & 1995 & 16 & 9 & 63 & 25 & 12 & 42 \\
\hline Davidsson et al & 1996 & 24 & 22 & 52 & 22 & 26 & $>6$ \\
\hline Jagose et al & 1998 & 6 & 6 & 50 & 50 & 0 & 108 \\
\hline Klow et al & 1998 & 49 & 40 & 25 & 43 & 29 & 61 \\
\hline Lovaria et al & 1999 & 69 & 50 & 45 & 23 & 32 & 112 \\
\hline Birrer et al & 2002 & 27 & 22 & 37 & 37 & 26 & 12 \\
\hline Fremuth et al & 2002 & 97 & 89 & 6 & 68 & 32 & 18 \\
\hline Surowiec et al & 2003 & 14 & 14 & 36 & 43 & 21 & 24 \\
\hline De Fraissinette et al & 2003 & 70 & 50 & 14 & 74 & 12 & 39 \\
\hline Kumar et al & 2003 & 20 & 12 & 85 & 5 & 10 & 68 \\
\hline Hughes et al & 2004 & 35 & 23 & 35 & 58 & 8 & 15 \\
\hline Alhadad et al & 2005 & 59 & 47 & 24 & 39 & 37 & 84 \\
\hline Tanaka et al & 2007 & 15 & 10 & 33 & 47 & 20 & 60 \\
\hline Kim et al & 2008 & 16 & 8 & 6 & 74 & 20 & 24 \\
\hline Davies et al & 2008 & 29 & 29 & 19 & 67 & 14 & 44 \\
\hline Thatipelli et al & 2009 & 16 & 14 & 0 & 21 & 79 & 13 \\
\hline Barrier et al & 2010 & 30 & 24 & NA & $76 / 58$ & 42 & 57 \\
\hline Smit et al & 2013 & 51 & 45 & 5 & 43 & 52 & 12 \\
\hline Total & & $\mathrm{I}, 578$ & 918 & & & & \\
\hline
\end{tabular}

Note: This table was adapted from Rutherford's Vascular Surgery, 7th ed, Cronenwett JL, Johnston W, Optimal management of renal artery fibromuscular dysplasia, 2226-2242, Copyright Saunders, an imprint of Elsevier Inc. $(2010) .{ }^{14}$

Abbreviation: NA, data not available.

gynecomastia, ${ }^{9}$ further suggesting hormonal imbalance as part of the etiology of FMD.

In the US FMD Registry, $37 \%$ of patients were current or former smokers compared with the rate of $18 \%$ reported for US women. ${ }^{8}$ In a case-control study of 337 FMD patients, $30 \%$ smoked compared with $18 \%$ of controls. ${ }^{23}$ However, the mechanisms by which smoking contributes to FMD have not been elucidated.

The occurrence of renal FMD in siblings and identical twins suggests autosomal dominant inheritance, with incomplete penetrance and variable clinical symptoms. ${ }^{24}$ Further, a US FMD Registry study reported a 7\% incidence in relatives. ${ }^{8}$ Importantly, stroke (54\%), aneurysm (24\%), and sudden death (20\%) were also common in firstdegree and second-degree relatives. FMD can be easily overlooked in asymptomatic relatives. ${ }^{25}$ Polymorphisms in the angiotensin-converting enzyme (ACE) insertion allele, ACE-I, and associations with HLA-Drw6 have been reported. ${ }^{26}$ Several groups are presently delineating other gene patterns predisposing to development of FMD. ${ }^{27}$

\section{Differential diagnosis}

Important differential diagnoses rely on associated phenotypic traits, including: the characteristic skin lesions in type 1 neurofibromatosis $;{ }^{28}$ acrogeric dysmorphism, skin elasticity, and distal joint laxity in vascular Ehlers-Danlos syndrome; ${ }^{29}$ and facial dysmorphism, supra-aortic stenosis, and the behavior characteristic of Williams syndrome. ${ }^{30}$ Genetic tests can also be used to rule out these conditions. Vasculitis is normally associated with an acute phase reaction.

\section{Pathology}

Histologically, the three main types of dysplasia in FMD are classified according to the arterial wall layer mainly 
Table 2 Results of open surgery for fibromuscular dysplasia in adults

\begin{tabular}{|c|c|c|c|c|c|c|c|}
\hline Series & Year & $\begin{array}{l}\text { Patients } \\
\text { (n) }\end{array}$ & $\begin{array}{l}\text { Female } \\
\text { (n) }\end{array}$ & $\begin{array}{l}\text { Cure } \\
\text { (\%) }\end{array}$ & $\begin{array}{l}\text { Improvement } \\
\text { (\%) }\end{array}$ & $\begin{array}{l}\text { Failure } \\
\text { (\%) }\end{array}$ & $\begin{array}{l}\text { Length of follow- } \\
\text { up (months) }\end{array}$ \\
\hline Buda et al & 1976 & 42 & NA & 76 & 14 & 10 & 72 \\
\hline Stoney et al & 1978 & 24 & 22 & 38 & 52 & 10 & 36 \\
\hline Bergentz et al & 1979 & 40 & NA & 66 & 24 & 10 & 36 \\
\hline Lawrie et al & 1980 & 113 & NA & 43 & 24 & 33 & 49 \\
\hline Jakubowski et al & $198 \mid$ & 75 & 64 & 50 & 22 & 36 & 72 \\
\hline Stoney et al & 1981 & 78 & 64 & 66 & 32 & 1 & 67 \\
\hline Stanley et al & 1982 & 144 & 133 & 55 & 39 & 6 & 60 \\
\hline Bardram et al & 1985 & 17 & 17 & 65 & 18 & 18 & 120 \\
\hline Lüscher et al & 1986 & 33 & 26 & 52 & 45 & 3 & 30 \\
\hline Morin et al & 1986 & 22 & 16 & 48 & 48 & 5 & 60 \\
\hline Novick et al & 1987 & 120 & 91 & 63 & 30 & 7 & 36 \\
\hline Van Bockel et al & 1987 & 53 & 40 & 53 & 34 & 13 & 77 \\
\hline Hägg et al & 1987 & 22 & 22 & 55 & 36 & 9 & 36 \\
\hline Hansen et al & 1992 & 43 & 31 & 43 & 49 & 8 & 24 \\
\hline Murray et al & 1994 & 68 & 61 & 74 & 23 & 2 & 90 \\
\hline Andersen et al & 1995 & 40 & 35 & 33 & 57 & 10 & 40 \\
\hline Wong et al & 1999 & 19 & 18 & 31 & 58 & 11 & 56 \\
\hline Reiher et al & 2000 & 101 & 80 & 36 & 31 & 33 & 66 \\
\hline Chiche et al & 2003 & 30 & 19 & 96 & 0 & 4 & 62 \\
\hline Marekovic et al & 2004 & 72 & 56 & 80 & 10 & 10 & 132 \\
\hline Carmo et al & 2005 & 26 & 22 & 27 & 60 & 13 & 29 \\
\hline Lacombe and Ricco & 2006 & 25 & 15 & 84 & 12 & 4 & 69 \\
\hline Crutchley et al & 2007 & 37 & 30 & 15 & 65 & 20 & 34 \\
\hline Robinson et al & 2011 & 24 & 17 & NA & 94 & 6 & 99 \\
\hline Balzer et al & 2012 & 17 & 16 & NA & 73 & 27 & 50 \\
\hline Total & & $\mathrm{I}, 285$ & 895 & & & & \\
\hline
\end{tabular}

Note: This table was adapted from Rutherford's Vascular Surgery, 7th ed, Cronenwett JL, Johnston W, Optimal management of renal artery fibromuscular dysplasia, 2226-2242, Copyright Saunders, an imprint of Elsevier Inc. (20I0). ${ }^{14}$

Abbreviation: NA, data not available.

affected by collagen deposition, ie, intimal, medial, and adventitial. ${ }^{19,31}$ The intimal form accounts for about $10 \%$ and occurs without sex difference. Medial dysplasia (accounting for about $80 \%$ of cases) occurs as areas with a thinned medial wall layer alternating with thickened fibromuscular ridges containing collagen (Figure 3). Adventitial FMD is uncommon. However, few dysplasias are currently examined histologically, so an angiographic diagnostic classification has been suggested based on differentiation between unifocal and multifocal appearance. ${ }^{32}$ Unifocal FMD (Figure 2) has less of a female predominance and is diagnosed more often in younger individuals, with better short-term and long-term results from treatment than multifocal FMD (Figure 1). ${ }^{32}$

\section{Pathophysiology}

In the multifocal type, multiple septa in the renal arteries may together induce a significant reduction in renal perfusion in patients with FMD, resulting in renovascular hypertension, but the degree of renal artery stenosis is impossible to evaluate from imaging. $4,7,12,14$

Subsequent reduction of arterial perfusion pressure by the unifocally or multifocally stenosed renal artery leads to activation of the renin-angiotensin-aldosterone system, with volume expansion and hypertension. This triggers mechanisms such as increased production of endothelin-1, local activation of the renin-angiotensin-aldosterone system, arterial wall remodeling, and oxidative stress, all helping to sustain the hypertension, ${ }^{33}$ which now depends

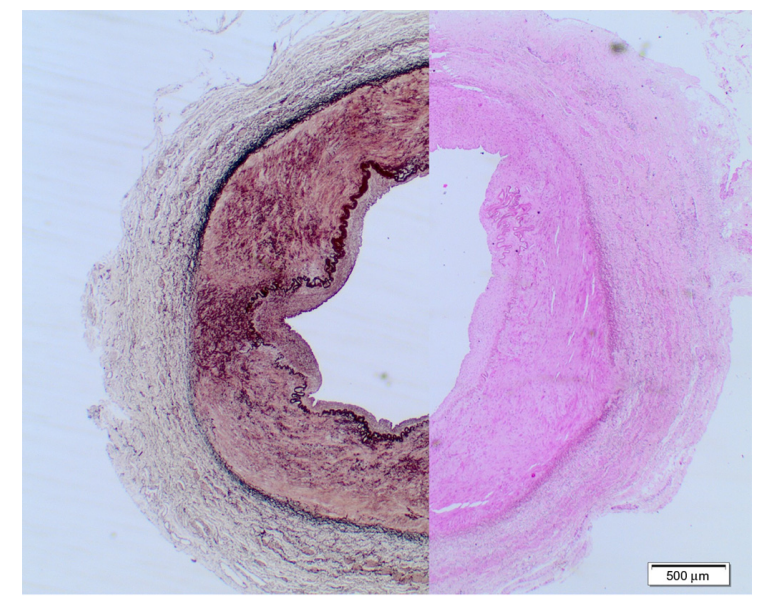

Figure 3 Medial fibrodysplasia with dense fibrous connective tissue in the outer layer of the medial layer, disordered inner medial smooth muscle, and collagen deposition. Composite of hematoxylin and elastin staining.

Note: (Courtesy of Dr J Malina, Department of Pathology, Skåne University Hospital, Malmö, Sweden). 
not only on the renin-angiotensin-aldosterone system but also on the local vasoconstrictive and importantly proliferative effects in the arterial/arteriole wall, gradually leading to resistance to therapy. ${ }^{34}$ Inflammatory mediators are increased in renovascular hypertension, ${ }^{35}$ but neopterin and endothelin-1 levels are lower in renovascular hypertension due to FMD than in atherosclerotic renal artery stenosis. ${ }^{35}$

\section{Natural history}

Data on the risk of progression of stenosis and deteriorating renal function are scarcer in patients with FMD than in those with atherosclerotic renal artery stenosis, but indicate that progression is less severe in FMD. ${ }^{4}$ Serial angiograms have confirmed progression of FMD in all ${ }^{36}$ or up to $40 \%$ of cases, ${ }^{37}$ and about $25 \%$ of subjects with asymptomatic FMD develop hypertension within 4 years..$^{6,7}$ Aneurysms $^{8}$ and dissection $^{8}$ are rather frequent as secondary manifestations of FMD, but complete occlusion, ${ }^{38}$ renal infarction, ${ }^{39}$ severe renal insufficiency, ${ }^{21,40}$ and regression of stenosis ${ }^{41}$ have been reported infrequently.

\section{Clinical picture and physical examination}

Arterial hypertension of acute onset or high blood pressure that is increasingly difficult to treat suggests the presence of a specific cause of blood pressure elevation. Such secondary hypertension can be identified in about $5 \%$ of adult hypertensive patients. ${ }^{13,42,43}$ Renovascular hypertension caused by one or more stenoses of the extrarenal arteries is the second most common cause of secondary hypertension (after renal parenchymal disease) and occurs in approximately $2 \%$ of adult hypertensive patients referred to specialized centers. ${ }^{13,42}$

\section{Blood pressure measurement}

Blood pressure should be measured at least twice in the sitting position, and home or 24-hour blood pressure measurements are encouraged to rule out white coat hypertension. ${ }^{13}$ Measurement of serum creatinine, calculation of estimated glomerular filtration rate, and testing for microalbuminuria are recommended in all hypertensive patients..$^{13,42}$

\section{Diagnostic evaluation}

The recent multicenter studies ${ }^{1-3}$ have implications for optimal selection of patients with hypertension and renal artery stenosis for medical, endovascular, and even open surgery. All diagnostic tools are in some way subjective, but at least in atherosclerotic cases, correct diagnosis of moderate to severe hypertension and renal artery stenosis of at least $60 \%-70 \%$ of the lumen area is important because treatment of stenosis of less than $60-70 \%$ leads to no clinical benefit. Appropriate patient selection is crucial to obtain clinical benefit from revascularization of hemodynamically relevant renal artery stenosis. Importantly, there is a difference in work-up according to whether atherosclerotic renal artery stenosis or FMD is suspected. 4,7,12,14

\section{Renal ultrasound}

Ultrasonography allows determination of longitudinal kidney size. A difference of $>1.5 \mathrm{~cm}$ between the sizes of the two kidneys is usually considered diagnostic and is found in $60 \%-70 \%$ of patients with renovascular hypertension. ${ }^{44}$

Color Doppler ultrasonography can often detect stenosis of the renal artery, particularly when localized close to the vessel origin. ${ }^{45}$ It also allows determination of the resistance index, which predicts the outcome of angioplasty and stenting in atherosclerotic renal artery stenosis. ${ }^{45}$ An increased resistance index suggests structural abnormalities in the small vessels of the kidney, and benefit from renal revascularization has been reported in patients with a resistance index $<80$. ${ }^{46}$ However, this index has not been evaluated in FMD patients. In a study of more than 300 patients using both duplex ultrasonography and angiography, peak systolic velocity and the systolic renal to aortic ratio was accurate for diagnosing a $60 \%$ renal artery stenosis. Specific data for 14 FMD patients in this study were not provided. ${ }^{45}$ In atherosclerotic renal artery stenosis, ultrasonographic evaluation may therefore identify the majority of patients with less than $60 \%-70 \%$ stenosis, in whom further investigations are not needed.

However, more caution is warranted in patients with suspected secondary hypertension caused by FMD. Limitations of duplex ultrasonography of the renal artery include its dependence on operator skill, the fact that it may be unsuccessful in $20 \%$ of patients because of problems visualizing branches or accessory renal arteries, and the difficulty or impossibility of imaging obese patients or those with intervening bowel gas. ${ }^{47}$ Because of these limitations and the fact that the distal renal artery and branch lesions are not optimally diagnosed by ultrasound, this technique cannot exclude FMD lesions. Changes in the mid section of the renal artery may well indicate a FMD lesion, but can also be explained by vessel tortuosity. ${ }^{48}$ Intravascular ultrasound is useful for distinguishing renal FMD from vasculitis and hypoplasia. ${ }^{49}$ However, the method is in limited clinical use. 


\section{Captopril renography}

The sensitivity and specificity of captopril renography decrease in the presence of renal failure, bilateral disease, branch artery lesions, and a solitary functioning kidney. Although data exist from studies of patients with renal artery stenosis due to FMD, captopril renography is no longer recommended as a first-line method owing to its low sensitivity and specificity, and the same applies to renin measurements. ${ }^{13,50}$

\section{Magnetic resonance angiography}

Magnetic resonance angiography (MRA) is a noninvasive imaging technique. A negative contrast-enhanced MRA probably excludes significant renal artery stenosis, but false-positive results due to turbulence are common, so MRA may overestimate the degree of renal artery stenosis..$^{11,32,51}$ MRA can only identify vessels as small as $2-2.5 \mathrm{~mm}$, so has limited resolution for distal and intrarenal arteries. ${ }^{11,21,52}$ Gadolinium-enhanced MRA has better specificity and sensitivity than ultrasound or scintigraphy, and is as efficient as computed tomographic (CT) angiography for detection of renal artery stenosis. ${ }^{50}$ However, given that the resolution of MRA is inadequate for visualization of branch vessel involvement, its usefulness for exclusion of FMD has been questioned (Figure 4). ${ }^{11}$ Gadolinium toxicity also precludes use of MRA in patients with severe renal impairment. Angeretti et $a^{153}$ reported that breath hold contrast-enhanced MRA is equal in diagnostic accuracy to noncontrast-enhanced electrocardiography gated steady-state free precision and respiratory triggered MRA, and even considered maximum intensity projections as being superior.

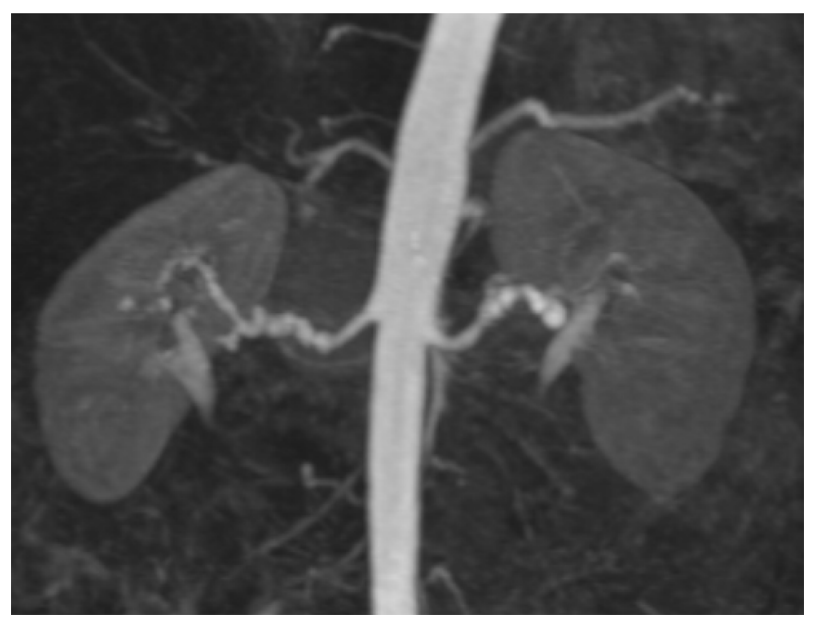

Figure 4 Magnetic resonance angiography, raising suspicion for bilateral fibromuscular dysplasia.

Notes: The right renal artery changes caused significant pressure gradients and were treated with percutaneous transluminal angioplasty. Note the absence of intrarenal branches, that are affected in $25 \%$ of patients with fibromuscular dysplasia and are not visualized with magnetic resonance angiography.

\section{CT angiography}

CT angiography has sensitivity comparable with that of MRA, but requires radiation and infusion of a potentially nephrotoxic contrast substance. CT angiography depicts both the lumen and the vessel wall but has limited resolution for the distal and intrarenal arteries. ${ }^{7,12}$ In some centers, MRA or CT angiography is now used as premapping before invasive treatment after duplex ultrasonography has suggested renal artery stenosis. ${ }^{50}$ Nevertheless, when the index of clinical suspicion is high, neither test can exclude FMD. None of these methods is reliable in the $25 \%$ of FMD patients with intrarenal stenosis.

\section{Renal angiography}

When one of the aforementioned screening examinations raises strong suspicion of renal artery stenosis, or when a fairly young FMD patient is evaluated and there is a strong clinical indication to proceed to revascularization, intra-arterial digital subtraction angiography should be performed for exclusion or confirmation. This invasive procedure is still the gold standard for detection of renal artery stenosis caused by FMD. ${ }^{7,11}$ FMD lesions are typically truncal or distal, whereas atherosclerotic lesions are more often proximal or ostial., ${ }^{4,32}$ Angiography is especially useful in evaluation of branch vessel disease. Angiography is a twodimensional analysis and therefore gives only an educated estimate of the degree of stenosis, which might help explain the difficulties in selecting patients who would benefit from treatment in recent trials. ${ }^{1-3}$ Additionally, the potential hemodynamic significance of the multiple stenoses often seen in FMD is almost impossible to evaluate.

\section{Pressure gradients}

Intra-arterial measurement of the pressure gradient over the stenosis, such as performed before percutaneous transluminal angioplasty in the iliac arteries,${ }^{54}$ is recommended in renal artery stenosis. ${ }^{55}$ Different methods for measuring pressure gradients have been used, ${ }^{56,57}$ and there is no consensus regarding the level indicating a hemodynamically significant stenosis. A distal aortic pressure ratio $<0.90$ has been correlated with increased renin levels in the renal vein, ${ }^{58}$ but pressure gradients could not be used to select patients for successful recanalization of atherosclerotic renal artery stenosis in the recent CORAL trial. ${ }^{3}$ However, prolonged hypertension leads to proliferative effects in the arterial/arteriole wall, resulting in resistance to therapy. Nevertheless, a mean pressure gradient of $>10 \mathrm{mmHg}$ over the stenosis predicts a favorable response to dilatation, and a persistent pressure gradient after an endovascular procedure indicates a higher risk of restenosis. ${ }^{59}$ 


\section{Treatment}

The treatment options for renal FMD are medical, endovascular, and surgical. Treatment of all renovascular hypertension is controversial due to difficulties in predicting the blood pressure response to renal revascularization in individual patients. ${ }^{1-3,7,11}$ In FMD, invasive endovascular or surgical treatment should be considered when hypertension cannot be controlled with medication, in those who are intolerant of or noncompliant with medication, and in those with impaired renal function or ischemic nephropathy. ${ }^{7,11}$

\section{Medical therapy}

Controlled trials have convincingly shown that lowering blood pressure reduces cardiovascular morbidity and mortality. ${ }^{13,60}$ All patients with renovascular hypertension caused by FMD are therefore candidates for antihypertensive treatment in accordance with current European ${ }^{13}$ and $\mathrm{US}^{42}$ guidelines. Blood pressure should be reduced to $<140 / 90 \mathrm{mmHg}$ in hypertensive patients, and according to European recommendations, ${ }^{13}$ further to $<140 / 85 \mathrm{mmHg}$ in patients with diabetes. Current guidelines ${ }^{13,42}$ specify five groups of first-line antihypertensive treatment, ie, ACE inhibitors, angiotensin II receptor blockers, calcium channel blockers, diuretics, and (in the European guidelines) beta blockers. ${ }^{13}$ All of these drugs can be used in the treatment of renovascular hypertension due to FMD.

Thiazide diuretics and calcium antagonists can be used with possible addition of a renin-angiotensin-aldosterone system blocker, an ACE inhibitor, or an angiotensin II receptor blocker. However, these should not be used during pregnancy. Such treatment lowers blood pressure in the majority of patients with renovascular hypertension. In patients with bilateral disease or stenosis of a single kidney, blockade of the renin-angiotensin-aldosterone system requires caution because of the risk of compromised renal function. ${ }^{61}$

\section{Endovascular treatment in adults}

Percutaneous transluminal renal angioplasty (PTRA, Figures 2, 3, and 5) has become the treatment of choice for renovascular hypertension caused by FMD. ${ }^{11,62}$ The main reason for treating FMD is unsatisfactorily controlled hypertension. Progressive loss of renal function is less likely in FMD than in atherosclerotic renovascular hypertension. ${ }^{63}$

\section{Technical considerations}

The micropuncture technique should be used to avoid groin hematoma, which is the most common $(3 \%-26 \%)^{11,64-66}$ but often preventable complication of PTRA. To ensure optimal

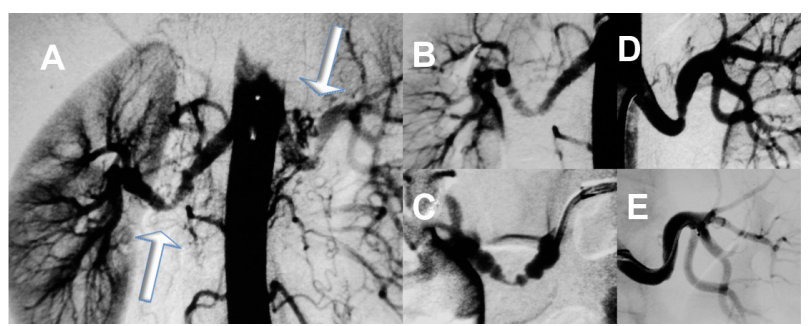

Figure 5 Angiography of a pregnant woman (week 16) with uncontrolled hypertension and bruits over the renal arteries.

Notes: Angiography with lead aprons covering the lower abdomen and as little radiation and contrast as possible showed bilateral fibromuscular dysplasia (A), arrows, which was treated with percutaneous transluminal angioplasty. Different stages of treatment are shown (B-D). The radiation to the fetus was $<0.5 \mathrm{mSv}$, hypertension improved, and the pregnancy was completed successfully. Post partum control showed restenosis that required repeat percutaneous transluminal angioplasty bilaterally $(\mathbf{E})$ with persisting good results thereafter.

compression after the procedure, the puncture position should be angiographically controlled before "larger" catheters or introducers are advanced. Low-profile 0.014 inch or 0.018 inch guidewire systems are used to reduce vasospasm. FMD patients are often younger and have more pronounced vasoreactivity than those with atherosclerosis. Therefore, renal vasospasm is common, and premedication with dihydropyridine or repeated doses of nitroglycerin $0.15 \mathrm{mg}$ may be required in hemodynamically stable patients, not only after catheterization. FMD stenoses most often occur in the middle portion of the main renal artery. If the distal renal artery or its branches are affected, use of multiple guide wires may be necessary. The kissing balloon technique can be used in the branches. ${ }^{64,67}$

\section{Stenting}

PTRA alone normally provides good results, in that pressure gradients are completely abolished and there is no indication for stent placement (Table 1). ${ }^{14}$ Indications for stenting of FMD lesions include severe procedural complications, persistent pressure gradients after repeated attempts at angioplasty, and small aneurysms in the renal artery. ${ }^{14}$ No value of drug-eluting stents has been reported.

\section{Procedure-related complications}

Groin hematoma is the most common complication, and dissection occurs infrequently (in $1.4 \%-6.7 \%$ of procedures). ${ }^{11,21,65}$ Few cases require repeated or prolonged balloon treatment, and only extensive expanding dissection requires stent deployment and fixation. ${ }^{11}$

Rupture of the renal artery is uncommon $(2 \%-6 \%)^{11,21,65}$ and occurs most often in association with complex FMD lesions. Some of these small ruptures stop leaking after 
prolonged balloon treatment, whereas others require stents, covered stents, or emergency open surgery after the balloon has achieved initial hemostasis.

The use of cutting balloons is definitely not a first choice in patients with FMD given that ruptures, especially of hypoplastic arteries, have been reported with their use. ${ }^{68-70}$ CT angiography, MRA, and intravascular ultrasound may add information on hypoplasia and wall thickness.

Branch occlusion is seen in $1 \%-5 \%$ of patients with FMD after PTRA, ${ }^{11,21,65}$ but most of these patients have a favorable outcome. Thrombosis of the main renal artery after endovascular reconstruction in adults is very rare. Bonelli et $\mathrm{al}^{65}$ reported occurrence of minor nonocclusive thrombotic material in the renal artery after PTRA in five of 105 patients with FMD.

\section{Early outcome}

Noncontrolled series on endovascular treatment of FMD have included $>1,500$ patients (Table 1), with two studies reporting on more than 100 patients each. ${ }^{65,71}$ The age and sex distribution differ in these reports, and it is hard to determine which types of FMD were treated, which affects outcome. In addition, recommendations on how to present outcome criteria have changed over time, making interpretation of results even more difficult. ${ }^{72}$ The male to female ratio in the compiled data (Table 1) was 1:4.4, and $25 \%$ of cases had bilateral FMD. Some studies have also reported on the diseased side in unilateral FMD. ${ }^{11,21,73}$ The right renal artery was affected in $81 \%$ of cases, and the left renal artery in $19 \%$.

PTRA can be performed with good results (Table 1), not only for main artery lesions but also when branch arteries are affected. ${ }^{21,65}$ However, patients with branch artery involvement show less pronounced blood pressure responses and higher restenosis rates. ${ }^{21}$

Comparisons of different series are limited because of the large variation in selection criteria and length of follow-up. "Cure", "improvement", and "benefit" are also defined differently. ${ }^{72}$ In a systematic review of FMD treatment, ${ }^{11}$ cure rates were around $65 \%$ in 30-year-old patients and only about $20 \%$ in 55 -year-old patients. This obvious reduction in cure rate with increasing age is also reported elsewhere..$^{32,74,75}$ The systematic review also reported a decrease in cure rate from approximately $60 \%$ in a $1980-1985$ series to about $30 \%$ in more recent series, perhaps reflecting changes in the definition of cure. ${ }^{11}$ Treatment is likely to cure hypertension in young individuals, but stricter criteria for invasive treatment should be used in older patients with FMD. The more strict treatment criteria recommended for atherosclerotic renal artery stenosis ${ }^{1-3}$ might perhaps be considered in older FMD patients.

\section{Late outcome}

Renal function was unchanged during follow-up..$^{32}$ Longterm durability and the initial effect after PTRA is good in patients with the "string of beads" appearance in the main artery; however, for more complex and branch lesions, the results are acceptable but redo procedures are needed more frequently (Figure 5).

Bonelli et al reported that $6 \%$ of their 105 patients required redo procedures during 4 years of follow-up ${ }^{65}$ while Alhadad et al found that although 34\% of their patients required a second and often planned PTRA procedure, only two patients required redo PTRA after more than 4 years of follow-up. ${ }^{21}$ The one-year cure rate is dependent on the angiographic type of FMD; 15/28 (54\%) patients with unifocal FMD versus only 13/50 (26\%) with multifocal FMD were cured in a report by Savard et al. ${ }^{32}$

\section{Surgery}

Surgical revascularization for FMD is currently reserved for patients with severe complications of PTRA, such as thrombosis, perforation, or dissection that cannot be handled with endovascular techniques. Open surgery should also be considered after repeated failure or restenosis following PTRA, recoil, and no effect on stenosis following endovascular treatment. In experienced groups, the results of operative treatment after failure of PTRA are favorable. ${ }^{75-79}$

\section{Techniques}

Details on reimplantation of a renal artery, aortorenal bypass, and autotransplantation are given elsewhere. ${ }^{14}$ Centers performing endovascular treatment need to have open operative techniques available, demanding further centralization of PTRA. The need for centralization will become more evident as recent published multicenter studies ${ }^{1-3}$ would probably reduce the number of referrals for atherosclerotic renal artery stenosis.

\section{Results of open surgery}

Published series on open surgery (Table 2) include more than 1,200 patients and report on aortorenal bypass, ${ }^{77-80} \mathrm{branch}$ artery reconstructions, ${ }^{81,82}$ and autotransplantation. ${ }^{78,83,84}$ Regardless of the method used, the early outcome is excellent. The more recent series mainly include patients who have undergone unsuccessful PTRA. The proportion of cured patients has been somewhat lower during the last 
10 years. However, because patients in these series are older, have had a longer duration of hypertension, and have more complex lesions, PTRA is now used for main artery lesions.

\section{Complications of open surgery}

Renal failure ${ }^{75,77,79,81,84}$ and a fatal outcome $81,83,84$ are both very uncommon after surgery for FMD. Overall morbidity from surgery is $19 \%-28 \%$, and is mainly caused by minor complications such as urinary tract infection and postoperative pneumonia. ${ }^{77,83}$ Early postoperative occlusion after FMD reconstruction is seen in $3.8 \%-13 \%$ of cases, and more often with venous grafts than with arterial autografts. ${ }^{77,80,83}$ Reiher et al detected nine unsuspected thromboses in 90 reconstructed patients on routine postoperative angiography ${ }^{83}$

Late restenosis and the need for redo procedures have become less common as most anastomoses are now made in an ovoid shape. Restenosis has been reported in $0 \%-16 \%$ of cases, ${ }^{77,78,80,83}$ and $1 \%-15 \%$ of patients require a redo procedure. ${ }^{77,80,83,84}$ Late vein graft dilatations were reported in $20 \%-44 \%$ in an early series of aortorenal bypass in adults, ${ }^{85}$ but not in the last decade, ${ }^{79,81,83}$ perhaps reflecting that FMD patients are now older and have a longer duration of hypertension. Pseudoaneurysms (Figure 6) are infrequently reported.

\section{FMD and aneurysms}

A large proportion of patients have FMD with the "string of beads" appearance, ie, small aneurysmal areas interspaced by webs. "Macroaneurysms" with obvious aneurysmal

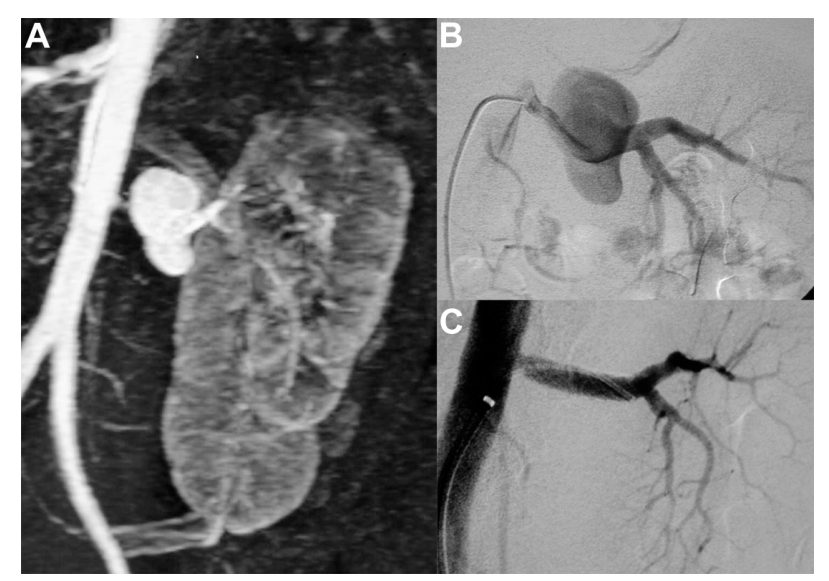

Figure 6 Endovascular treatment of renal artery pseudoaneurysm.

Notes: Woman with bilateral fibromuscular dysplasia who 15 years earlier had undergone patch angioplasty after failed endovascular treatment (pressure gradient $50 \mathrm{mmHg}$, recoiling) of the left renal artery, and nephrectomy of an atrophic right kidney. Routine follow-up 15 years later revealed a $3-4 \mathrm{~cm}$ pseudoaneurysm around the patch angioplasty $(\mathbf{A})$, which was able to be treated with endovascular placement of a covered stent graft $(\mathbf{B}, \mathbf{C})$ and had a good outcome. development are not infrequent; however, $8.5 \%-26.7 \%$ of patients with FMD have aneurysmal changes. ${ }^{8,19,82,83}$ Most renal artery aneurysms have a low risk of rupture, and few ruptured FMD lesions have been reported. ${ }^{86-88}$ How FMD-related aneurysms measuring 1-2 cm should be handled is uncertain. Conservative treatment may be successful. Aneurysms larger than $2 \mathrm{~cm}$ should probably be excluded. ${ }^{79,81,83}$ Renal artery aneurysms have occurred in $5 \%-12 \%$ of pediatric patients with FMD undergoing open surgery..$^{9,78,88}$

The endovascular experience is limited. Small aneurysms may shrink after successful PTRA of stenotic areas, and favorable outcomes have been reported with embolization $^{49,89}$ and stent grafts. ${ }^{90,91}$ Tsilimparis et $\mathrm{al}^{92}$ reported recently on 44 renal artery aneurysms, of which half were openly reconstructed, 19 were embolized with or without stent placement, and four were treated with covered stents. Aneurysmal size (2.5 cm versus $2.2 \mathrm{~cm})$, complications, and renal function did not differ during 21-27 months of follow-up.

\section{Pediatric renal artery stenosis and arterial dysplasia}

Renovascular disease is the most common cause of hypertension in children after thoracic aortic coarctation and renal parenchymal disease. ${ }^{11,93}$ Causes of renovascular hypertension are FMD, developmental renal artery stenosis, vascular neurofibromatosis type 1, Moyamoya disease, vasculitis such as Takayasu's disease, Alagille syndrome, and Williams syndrome. . $^{9,16,88,89} \mathrm{Up}$ to $40 \%$ of children with renovascular hypertension have developmental renal artery lesions with mid aortic syndrome and coexisting lesions in both the mesenteric and carotid arteries. ${ }^{94}$

\section{Endovascular treatment in children}

Published series on endovascular treatment in children and adolescents have included 237 patients, 150 of whom had FMD. ${ }^{14}$ The sex distribution in children is equal. Technical success rates are high in published series, with cure or improvement in about $80 \%-90 \%$ of cases. The majority of children have medial or perimedial dysplasia; however, the "string of beads" type of lesion is not frequent in children. Shroff et al reported long-segment stenosis in 60\%, ostial stenosis in $22 \%$, ostial and long-segment stenosis in $12 \%$, aneurysmal dilatation in $6 \%$, and webs in $6 \%$ of their series. ${ }^{16}$ McTaggart et al reported on 17 children, eight of whom had ostial lesions; the main renal artery was affected in eight cases, and three lesions were seen in branches. ${ }^{95}$ 
Follow-up of PTRA in children aged 13 months to 12 years demonstrates variable outcome. Benefit is frequently reported, but restenosis occurs in $27 \%-33 \%$ of cases, ${ }^{16,87}$ and branch lesions often require redo PTRA. ${ }^{16,87,96}$ Treatment of very young children to achieve a moderate improvement may allow open surgery to be delayed until an older age, when the procedure can be performed with better long-term results.

\section{Open surgery for pediatric renovascular hypertension}

In the University of Michigan Pediatric Renovascular Group's report, ${ }^{9} 12$ of 97 children undergoing open surgery had multisegmental disease, six had aneurysms, 70 had ostial lesions, 15 had changes in the main artery, and 18 had branch involvement. ${ }^{9}$ Stenosis was unilateral in $58 \%$ of cases, and

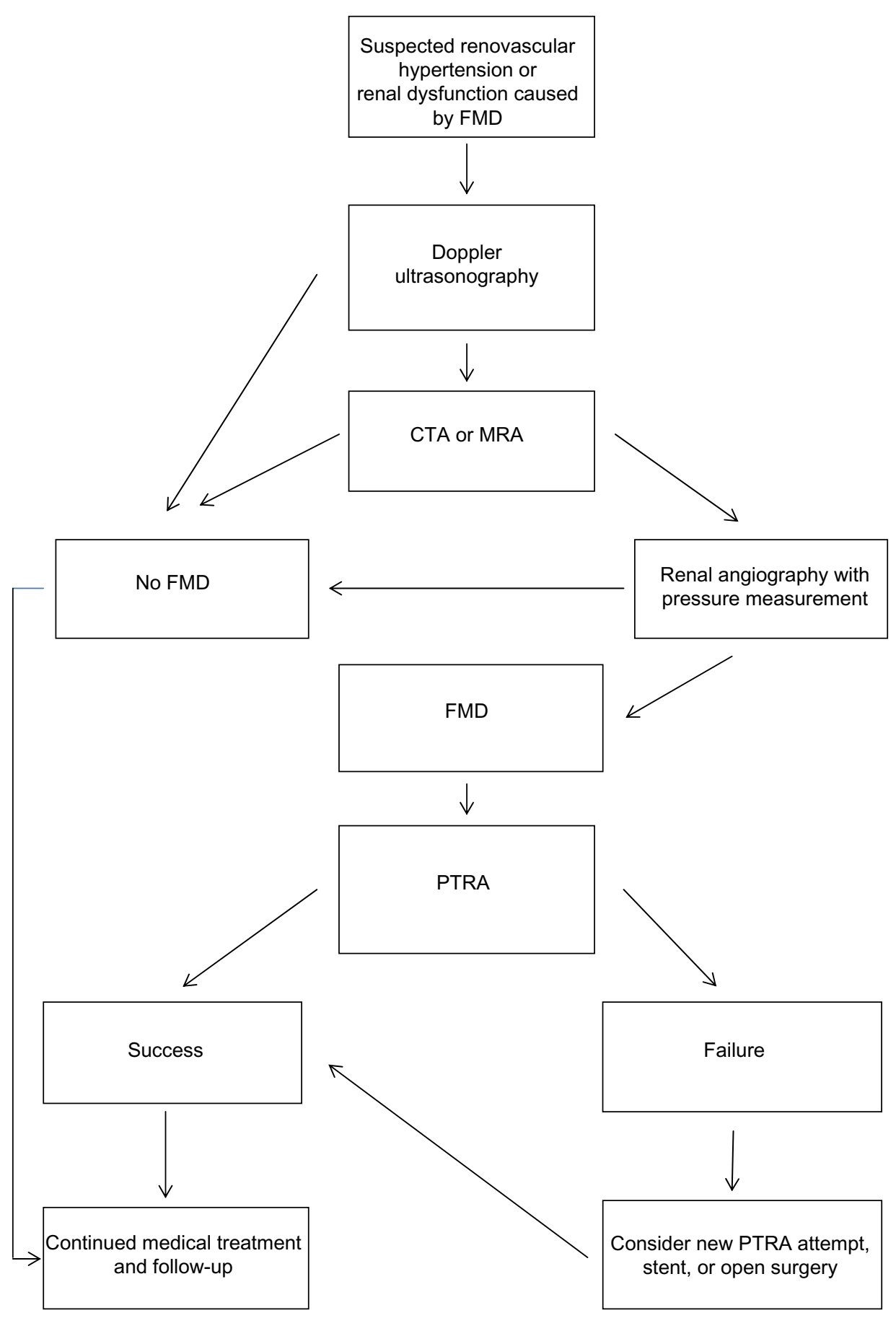

Figure 7 Suggested management principles for fibromuscular dysplasia.

Abbreviations: FMD, fibromuscular dysplasia; CTA, computed tomography angiography; MRA, magnetic resonance angiography; PTRA, percutaneous transluminal renal angioplasty. 
bilateral in $42 \%$. Few girls younger than 10 years were treated, and in that age group, boys were three times more likely to be affected. No sex difference was noted in those aged 10-17 years.

Open surgery series have included 439 children and adolescents, 379 of whom had FMD. The early series included a large proportion $(40 \%-50 \%)$ who underwent nephrectomy, ${ }^{97,98}$ whereas Stanley et al reported on 97 children with irreversible renal disease requiring planned $(n=11)$ or unplanned nephrectomy $(n=1)$ due to failure of a reconstruction. ${ }^{9}$ Centers of excellence ${ }^{9,93}$ advocate direct aortorenal anastomosis if feasible, which was possible in 41 of 58 reconstructions. ${ }^{9}$ In 85 children, Lacombe used direct anastomosis in 17 cases and splenorenal anastomosis in $22 .{ }^{93}$ Long-term follow-up (1-10 years) shows a benefit of surgery in about $95 \%$ of cases and a minimal restenosis rate, in spite of continuing growth. Centralization of endovascular procedures and surgery is required in children.

\section{Conclusion}

In summary, the diagnostic work-up in suspected secondary hypertension (Figure 7) should include renal artery ultrasound. When FMD is suspected, further examination with CT angiography or MRA is often warranted but, as with ultrasound, neither technique reliably visualizes FMD in the branch arteries. Renal angiography may be required, and allows for PTRA, which is the treatment of choice for FMD in patients with renovascular hypertension or renal dysfunction. However, indications for invasive treatment in older FMD patients should perhaps be narrowed in the future, as in atherosclerotic renal artery stenosis.

\section{Disclosure}

The authors report no conflicts of interest in this work.

\section{References}

1. ASTRAL investigators. Revascularization versus medical therapy for renal-artery stenosis. $N$ Engl J Med. 2009;361(20): 1953-1362.

2. Bax L, Mali WP, Buskens E, et al; STAR Study Group. The benefit of STent placement and blood pressure and lipid-lowering for the prevention of progression of renal dysfunction caused by Atherosclerotic ostial stenosis of the renal artery. The STAR-study: rationale and study design. J Nephrol. 2003;16(6):807-812.

3. Cooper CJ, Murphy TP, Cutlip DE, et al; CORAL Investigators. Stenting and medical therapy for atherosclerotic renal-artery stenosis. $N$ Engl J Med. 2014;370(1):13-22.

4. Plouin PF, Perdu J, La Batide-Alanore A, et al. Fibromuscular dysplasia. Orphanet J Rare Dis. 2007;2:28.

5. Andreoni KA, Weeks SM, Gerber DA, et al. Incidence of donor renal fibromuscular dysplasia: does it justify routine renal angiography? Transplantation. 2002;73(7):1112-1116.

6. McKenzie GA, Oderich GS, Kawashima A, Misra S. Renal artery fibromuscular dysplasia in 2,640 renal donor subjects: a CT angiography analysis. J Vasc Interv Radiol. 2013;24(10):1477-1480.
7. Slovut DP, Olin JW. Fibromuscular dysplasia. $N$ Engl J Med. 2004;350(18):1862-1871.

8. Olin JW, Froehlich J, Gu X, et al. The United States Registry for Fibromuscular Dysplasia: results in the first 447 patients. Circulation. 2012;125(25):3182-3190.

9. Stanley JC, Criado E, Upchurch GR Jr, et al. Pediatric renovascular hypertension: 132 primary and 30 secondary operations in 97 children. J Vasc Surg. 2006;44(6):1219-1229.

10. De Fraissinette B, Garcier JM, Dieu V, et al. Percutaneous transluminal angioplasty of dysplastic stenoses of the renal artery: results on 70 adults. Cardiovasc Intervent Radiol. 2003;26(1): 46-51.

11. Trinquart L, Mounier-Vehier C, Sapoval M, Gagnon N, Plouin PF. Efficacy of revascularization for renal artery stenosis caused by fibromuscular dysplasia: a systematic review and meta-analysis. Hypertension. 2010;56(3):525-532.

12. Das CJ, Neyaz Z, Thapa P, Sharma S, Vashist S. Fibromuscular dysplasia of the renal arteries: a radiological review. Int Urol Nephrol. 2007;39(1):233-238.

13. Mancia G, Fagard R, Narkiewicz K, et al. The Task Force for the management of arterial hypertension of the European Society of Hypertension (ESH) and of the European Society of Cardiology (ESC). 2013 ESH/ESC Guidelines for the management of arterial hypertension. J Hypertens. 2013;31(7):1281-1357.

14. Lindblad B, Gottsäter A. Optimal management of renal artery fibromuscular dysplasia. In: Cronenwett JL, Johnston W, editors. Rutherford's Vascular Surgery. 7th ed. Philadelphia, PA, USA: Saunders; 2010.

15. Tyagi S, Kaul UA, Satsangi DK, Arora R. Percutaneous transluminal angioplasty for renovascular hypertension in children: initial and longterm results. Pediatrics. 1997;99(1):44-49.

16. Shroff R, Roebuck DJ, Gordon I, et al. Angioplasty for renovascular hypertension in children: 20-year experience. Pediatrics. 2006;118(1): 268-275.

17. Sarkar R, Messina LM. Renovascular disease: pathology of renal artery occlusive disease. In: Ernst CB, Stanley JC, editors. Current Therapy of Vascular Surgery. 3rd ed. St Louis, MO, USA: Mosby; 1985.

18. Sottiurai V, Fry WJ, Stanley JC. Ultrastructural characteristics of experimental arterial medial fibroplasia induced by vasa vasorum occlusion. J Surg Res. 1978;24(3):167-177.

19. Vuong PN, Desoutter P, Mickley V, et al. Fibromuscular dysplasia of the renal artery responsible for renovascular hypertension: a histological presentation based on a series of 102 patients. Vasa. 2004;33(1):13-18.

20. Lüscher TF, Lie JT, Stanson AW, Houser OW, Hollier LH, Sheps SG. Arterial fibromuscular dysplasia. Mayo Clin Proc. 1987;62(10): 931-952.

21. Alhadad A, Mattiasson I, Ivancev K, Gottsäter A, Lindblad B. Revascularisation of renal artery stenosis caused by fibromuscular dysplasia: effects on blood pressure during 7-year follow-up are influenced by duration of hypertension and branch artery stenosis. J Hum Hypertens. 2005;19(10):761-767.

22. Kim ES, Olin JW, Froehlich JB, et al. Clinical manifestations of fibromuscular dysplasia vary by patient sex. A report of the United States Registry for fibromuscular dysplasia. J Am Coll Cardiol. 2013;62(21): 2026-2028.

23. Savard S, Azarine A, Jeunemaitre X, Azizi M, Plouin PF, Steichen O. Association of smoking with phenotype at diagnosis and vascular interventions in patients with renal artery fibromuscular dysplasia. Hypertension. 2013;61(6):1227-1232.

24. Bigazzi R, Bianchi S, Quilici N, Salvadori R, Baldari G. Bilateral fibromuscular dysplasia in identical twins. Am J Kidney Dis. 1998;32(6):E4.

25. Perdu J, Boutouyrie P, Bourgain C, et al. Inheritance of arterial lesions in renal fibromuscular dysplasia. J Hum Hypertens. 2007;2(5)1: 393-400.

26. Bofinger A, Hawley C, Fisher P, et al. Polymorphisms of the renin-angiotensin system in patients with multifocal renal arterial fibromuscular dysplasia. J Hum Hypertens. 2001;15(3):185-190. 
27. Persu A, Touzé E, Mousseaux E, Barral X, Joffre F, Plouin PF. Diagnosis and management of fibromuscular dysplasia: an expert consensus. Eur J Clin Invest. 2011;42(3):338-347.

28. Gutmann DH, Aylsworth A, Carey JC, et al. The diagnostic evaluation and multidisciplinary management of neurofibromatosis 1 and neurofibromatosis 2. JAMA. 1997;278(1):51-57.

29. Germain DP, Herrera-Guzman Y. Vascular Ehlers-Danlos syndrome. Ann Genet. 2004;47(1):1-9.

30. Lacolley P, Boutouyrie P, Glukhova M, et al. Disruption of the elastin gene in adult Williams syndrome is accompanied by a paradoxical reduction in arterial stiffness. Clin Sci (Lond). 2002;103(1):21-29.

31. Stanley JC, Gewertz BL, Bove EL, Sottiurai V, Fry WJ. Arterial fibrodysplasia histopathologic character and current etiologic concepts. Arch Surg. 1975;110(5):561-566.

32. Savard S, Steichen O, Azarine A, Azizi M, Jeunemaitre X, Plouin PF. Association between two angiographic subtypes of renal artery fibromuscular dysplasia and clinical characteristics. Circulation. 2012;126(25):2925-2927.

33. Higashi Y, Sasaki S, Nakagawa K, et al. Endothelial function and oxidative stress in renovascular hypertension. $N$ Engl J Med. 2002;346(25):1954-1962.

34. Morishita R, Higaki J, Miyazaki M, Ogihara T. Possible role of the renin-angiotensin system in hypertension and vascular hypertrophy. Hypertension. 1992;19 Suppl II:1162-1167.

35. Alhadad A, Guron G, Fortuna-Nowakowska E, et al. Transient rise in high sensitivity $\mathrm{C}$-reactive protein and interleukin-6, and long term decrease in endothelin-1 after angioplasty of renal artery stenosis. J Hypertens. 2007;25(9):1907-1914.

36. Goncharenko V, Gerlock AJ Jr, Shaff MI, Hollifield JW. Progression of renal artery fibromuscular dysplasia in 42 patients as seen on angiography. Radiology. 1981;139(1):45-51.

37. Schreiber MJ, Pohl MA, Novick AC. The natural history of atherosclerotic and fibrous renal artery disease. Urol Clin North Am. 1984;11(3):383-392.

38. Ropponen KM, Alafuzoff I. A case of sudden death caused by fibromuscular dysplasia. J Clin Pathol. 1999;52(7):541-542.

39. Sinnamon K, McNally D, Harty J. Fibromuscular dysplasia presenting as renal infarction. Kidney Int. 2007;72(10):1295-1296.

40. Mestres CA, Campistol JM, Ninot S, et al. Improvement of renal function in azotaemic hypertensive patients after surgical revascularization. Br J Surg. 1988;75(6):578-580.

41. Nemcek AA, Holmburg CE. Reversible renal fibromuscular dysplasia. AJR Am J Roentgenol. 1986;147(4):737-738.

42. James PA, Oparil S, Carter BL, et al. 2014 Evidence-based guideline for the management of high blood pressure in adults. Report from the panel members appointed to the Eighth Joint National Committee (JNC 8). JAMA. 2014;311(5):507-520.

43. Elliott WJ. Secondary hypertension: renovascular hypertension. In: Black H, Elliot W, editors. Hypertension: A Companion to Braunwald's Heart Disease. Philadelphia, PA, USA: Saunders Elsevier; 2007.

44. Krumme W, Blum U, Schwertfeger E, et al. Diagnosis of renovascular disease by intra-extrarenal Doppler scanning. Kidney Int. 1996;50(4):1288-1292.

45. AbuRahma AF, Srivastava M, Mousa AY, et al. Critical analysis of renal duplex ultrasound parameters in detecting significant renal artery stenosis. J Vasc Surg. 2012;56(4):1052-1060.

46. Radermacher J, Chavan A, Bleck J, et al. Use of Doppler ultrasonography to predict the outcome of therapy for renal artery stenosis. $N$ Engl J Med. 2001;344(6):410-417.

47. Hansen KJ, Tribble RW, Reavis SW, et al. Renal duplex sonography: evaluation of clinical utility. J Vasc Surg. 1990;12(3):227-236.

48. Lo R, Donaldson C. Vessel tortuosity causing false positives in detecting renal artery stenosis on Doppler ultrasound. Ultrasound $Q$. 2013;29(1):47-50.

49. Gowda MS, Loeb AL, Crouse LJ, Kramer PH. Complementary roles of color-flow duplex imaging and intravascular ultrasound in the diagnosis of renal artery fibromusculardysplasia. J Am Coll Cardiol. 2003;41(8):1305-1311.
50. Eklöf H, Ahlström H, Magnusson A, et al. A prospective comparison of duplex ultrasonography, captopril renography, MRA, and computed tomographic angiography in assessing renal artery stenosis. Acta Radiol. 2006;47(8):764-774.

51. Leung DA, Hoffmann U, Pfammatter T, et al. Magnetic resonance angiography versus duplex sonography for diagnosing renovascular disease. Hypertension. 1999;33(2):726-731.

52. Pei Y, Shen H, Li J, et al. Evaluation of renal artery in hypertensive patients by unenhanced MR angiography using spatial labeling with multiple inversion pulses sequence and by CT angiography. AJR Am J Roentgenol. 2012;199(5):1142-1148.

53. Angeretti MG, Lumia D, Canì A, et al. Non-enhanced MR angiography of renal arteries: comparison with contrast-enhanced MR angiography. Acta Radiol. 2013;54(7):749-756.

54. Tetteroo E, Haaring C, van der Graaf Y, et al. Intraarterial pressure gradients after randomized angioplasty or stenting of iliac artery lesions. Dutch Iliac Stent Trial Study Group. Cardiovasc Intervent Radiol. 1996;19(6):411-417.

55. Martin LG, Rundback JH, Sacks D, et al. Quality improvement guidelines for angiography, angioplasty and stent placement in the diagnosis and treatment of renal artery stenosis in adults. J Vasc Interv Radiol. 2002;13(11):1069-1083.

56. Nahman NS Jr, Maniam P, Hernandez RA Jr, et al. Renal artery pressure gradients in patients with angiographic evidence of atherosclerotic renal artery stenosis. Am J Kidney Dis. 1994;24(4): 695-699.

57. Gross CM, Kramer J, Weingärtner O, et al. Determination of renal arterial stenosis severity: comparison of pressure gradient and vessel diameter. Radiology. 2001;220(3):751-756.

58. De Bruyne B, Manoharan G, Pijls NH, et al. Assessment of renal artery stenosis severity by pressure measurements. J Am Coll Cardiol. 2006;48(9):1851-1855.

59. Mahmud E, Brocato M, Palakodeti V, Tsimikas S. Fibromuscular dysplasia of renal arteries: percutaneous revascularisation based on hemodynamic assessment with a pressure measurement guidewire. Catheter Cardiovasc Intervent. 2006;67(3):434-437.

60. Turnbull F; Blood Pressure Lowering Treatment Trialists' Collaboration. Effects of different blood-pressure-lowering regimens on major cardiovascular events: results of prospectively-designed overviews of randomised trials. Lancet. 2003;362(9395):1527-1535.

61. Ramos F, Kotliar C, Alvarez D, et al. Renal function and outcome of PTRA and stenting for atherosclerotic renal artery stenosis. Kidney Int. 2003;63(1):276-282.

62. Knipp BS, Dimick JB, Eliason JL, et al. Diffusion of new technology for the treatment of renovascular hypertension in the United States: surgical revascularization versus catheter-based therapy, 1988-2001. JVasc Surg. 2004;40(4):717-723.

63. Davidson RA, Barri Y, Wilcox CS. Predictors of cure of hypertension in fibromuscular renovascular disease. Am J Kidney Dis. 1996;28(3): 334-338.

64. Unsal A, Parildar M, Oran I, Oguz H, Memis A. Treatment of renal artery bifurcation stenosis due to fibromuscular dysplasia by kissing balloon technique and intrarenal stent deployment: a case report. Int J Angiol. 2002;11(1):86-88.

65. Bonelli FS, McKusick MA, Textor SC, et al. Renal artery angioplasty: technical results and clinical outcome in 320 patients. Mayo Clin Proc. 1995;70(11):1041-1052.

66. Birrer M, Do DD, Mahler F, Triller J, Baumgartner I. Treatment of renal artery fibromuscular dysplasia with balloon angioplasty: a prospective follow-up study. Eur J Vasc Endovasc Surg. 2002;23(2): $146-152$.

67. Smit JV, Wierema TK, Kroon AA, de Leeuw PW. Blood pressure and renal function before and after percutaneous transluminal renal angioplasty in fibromuscular dysplasia: a cohort study. $J$ Hypertens. 2013;31(6):1183-1188.

68. Oguzkurt L, Tercan F, Gulcan O, Turkoz R. Rupture of the renal artery after cutting balloon angioplasty in young women with fibromuscular dysplasia. Cardiovasc Intervent Radiol. 2005;28(3):360-363. 
69. Lupattelli T, Nano G, Inglese L. Regarding cutting balloon angioplasty of renal fibromuscular dysplasia: a word of caution. J Vasc Surg. 2005;42(5):1038-1039.

70. Tanemoto M, Abe T, Chaki T, Satoh F, Ishibashi T, Ito S. Cutting balloon angioplasty of resistant renal artery stenosis caused by fibromuscular dysplasia. J Vasc Surg. 2005;41(5):898-901.

71. Simonetti G, BonomoL, Cornalba GP, et al. L'angioplastica renale percutanea transluminale: esperienza italiana in 13 centri [Percutaneous transluminal renal angioplasty: Italian experience from 13 centers]. Radiol Med. 1993;86(4):503-508. Italian.

72. Rundback JH, Sacks D, Kent KC, et al. Guidelines for the reporting of renal artery revascularization in clinical trials. Circulation. 2002;106(12):1572-1585.

73. Surowiec SM, Sivamurthy N, Rhodes JM, et al. Percutaneous therapy for renal artery fibromuscular dysplasia. Ann Vasc Surg. 2003;17(6): 650-655.

74. Davies MG, Saad WE, Peden EK, Mohiuddin IT, Naoum JJ, Lumsden AB. The long-term outcomes of percutaneous therapy for renal artery fibromuscular dysplasia. J Vasc Surg. 2008;48(4):865-871.

75. Thatipelli MR, Huettl EA, McKusick MA, Misra S. Angioplasty for renal artery fibromuscular dysplasia in older hypertensive patients. Angiology. 2009;60(6):714-718.

76. Wong JM, Hansen KJ, Oskin TC, et al. Surgery after failed percutaneous renal artery angioplasty. J Vasc Surg. 1999;30(3):468-483.

77. Anderson CA, Hansen KJ, Benjamin ME, Keith DR, Craven TE, Dean RH Renal artery fibromuscular dysplasia: results of current surgical therapy. J Vasc Surg. 1995;22(3):207-216.

78. Lacombe M, Ricco JB. Surgical revascularization of renal artery after complicated or failed percutaneous transluminal renal angioplasty. J Vasc Surg. 2006;44(3):537-544.

79. Carmo M, Bower TC, Mozes G, et al. Surgical management of renal fibromuscular dysplasia: challenges in the endovascular era. Ann Vasc Surg. 2005;19(2):208-217.

80. Novick AC, Ziegelbaum M, Vidt DG, Gifford RW Jr, Pohl MA, Goormastic M. Trends in surgical revascularization for renal artery disease: ten years' experience. JAMA. 1987;257(4):498-501.

81. Crutchley TA, Pearce JD, Craven TE, Edwards MS, Dean RH, Hansen KJ. Branch renal artery repair with cold perfusion protection. J Vasc Surg. 2007;46(3):405-412.

82. Murray SP, Kent C, Salvatierra O, Stoney RJ. Complex branch renovascular disease: management options and late results. JVasc Surg. 1994;20(3):338-345.

83. Reiher L, Pfeiffer T, Sandemann W. Long-term results after surgical reconstruction for renal artery fibromuscular dysplasia. Eur J Vasc Endovasc Surg. 2000;20(6):556-559.
84. van Bockel JH, van Schilfgaarde R, Felthuis W, van Brummelen P, Hermans J, Terpstra JL. Long-term results of in situ and extracorporeal surgery for renovascular hypertension caused by fibrodysplasia. $J$ Vasc Surg. 1987;6(4):355-364.

85. Stanley JC, Ernst CB, Fry WJ. Fate of 100 aortorenal vein grafts: characteristics of late graft expansion, aneurysmal dilatation, and stenosis. Surgery. 1973;74(6):931-944.

86. Adams CW, Reidy J. Renal arterial pathology after percutaneous transluminal angioplasty. Atherosclerosis. 1987;63(2-3):153-157.

87. Courtel JV, Soto B, Niaudet P, et al. Percutaneous transluminal angioplasty of renal artery stenosis in children. Pediatr Radiol. 1998;28(1): 59-63.

88. Piercy KT, Hundely JC, Stafford JM, et al. Renovascular disease in children and adolescents. J Vasc Surg. 2005;41(6):973-982.

89. Serter S, Oran I, Parildar M, Memis A. Fibromuscular dysplasia-related renal artery stenosis associated with aneurysm: successive endovascular therapy. Cardiovasc Intervent Radiol. 2007;30(2):297-299.

90. Bisschops RH, Popma JJ, Meyerovitz MF. Treatment of fibromuscular dysplasia and renal artery aneurysm with the use of a stent-graft. JVasc Interv Radiol. 2001;12(6):757-760.

91. Bui BT, Olivia VL, Leclerc G, et al. Renal artery aneurysm: treatment with percutaneous placement of a stent-graft. Radiology. 1995;195(1):181-182.

92. Tsilimparis N, Reeves JG, Dayama A, Perez SD, Debus ES, Ricotta JJ 2nd. Endovascular vs open repair of renal artery aneurysms: outcomes of repair and long-term renal function. J Am Coll Surg. 2013;217(2): 263-269.

93. Lacombe M. Surgical treatment of renovascular hypertension in children. Eur J Vasc Endovasc Surg. 2011;41(6):770-777.

94. Stanley JC, Zelenock GB, Messina LM, Wakefield TW. Pediatric renovascular hypertension: a thirty-year experience of operative treatment. J Vasc Surg. 1995;21(2):212-227.

95. McTaggart SJ, Gulati S, Walker RG, Powell HR, Jones CL. Evaluation and long-term outcome of pediatric renovascular hypertension. Pediatr Nephrol. 2000;14(10-11):1022-1029.

96. Mali WP, Puijlaert CB, Kouwenberg HJ, et al. Percutaneous transluminal angioplasty in children and adolescents. Radiology. 1987;165(2): 391-394.

97. Stoney RJ, Cooke PA, String ST. Surgical treatment of renovascular hypertension in children. J Pediatr Surg. 1975;10(5):631-639.

98. Novick AC, Straffon RA, Stewart BH, Benjamin S. Surgical treatment of renovascular hypertension in the pediatric patient. $J$ Urol. 1978;119(6):794-799.
Therapeutics and Clinical Risk Management

\section{Publish your work in this journal}

Therapeutics and Clinical Risk Management is an international, peerreviewed journal of clinical therapeutics and risk management, focusing on concise rapid reporting of clinical studies in all therapeutic areas, outcomes, safety, and programs for the effective, safe, and sustained use of medicines. This journal is indexed on PubMed Central, CAS,

\section{Dovepress}

EMBase, Scopus and the Elsevier Bibliographic databases. The manuscript management system is completely online and includes a very quick and fair peer-review system, which is all easy to use. Visit http://www.dovepress.com/testimonials.php to read real quotes from published authors. 